\title{
REAL-TIME MONITORING OF WATER QUALITY USING SMART SENSORS: FEEDBACK OF LARGE PILOT LAB TESTS
}

\author{
AMANI ABDALLAH, ISAM SHAHROUR \& MARWAN SADEK \\ Civil and Geo-Environment Engineering Laboratory (LGCgE), \\ Lille University, France
}

\begin{abstract}
The control of the drinking water quality is a major concern for public health. This control is generally conducted in laboratory, which requires long time. This type of control is not adapted for accidental or malicious pollutions, which can have serious consequences to the population health. Therefore, accurate real-time control of the water quality is required for ensuring a safe water supply. This paper presents results obtained within the European project SmartWater4Europe for the analysis of the capacity of an optical-based device (EventLab, Optiqua) to detect water contamination by chemical substances. Analyses were conducted in a large-scale Pilot Lab, which allows the injection of chemical substances in a water circuit under controlled conditions. Tests conducted with 4 chemical products (cadmium chloride, mercury dichloride, sodium hypochlorite and glyphosate) at different concentrations showed the capacity of EventLab device to detect the injection of concentrations exceeding $5 \mathrm{mg} / \mathrm{L}$.

Keywords: real-time, monitoring, contaminant, water, refractive index, Optiqua.
\end{abstract}

\section{INTRODUCTION}

Access to safe drinking water is crucial for human health [1], [2]. Water contamination causes more than 14,000 deaths per day. In addition, drinking water infrastructure could be subjected to malicious acts by voluntary introduction of contaminants [3].Consequently, the real-time monitoring of the water quality is required to ensure both good water quality supply and to take early mitigation measurements in case of any water contamination [4]-[7].

The real-time detection of water contamination constitutes a complex task [8], because of the wide variety of contaminants (chemical, biological, radiological...) and the inherent difficulties to an early detection of each contaminant. Within the European Project SmartWater4Europe, we conducted a preliminary study using a large-scale Pilot Lab to explore the capacity of innovative devices to detect different kinds of water contamination. This paper presents the Pilot Lab and the results obtained with EventLab device, which is based on the measurement of the refractive index.

\section{EXPERIMENTAL DISPOSITIVE AND PROCEDURE}

\subsection{Presentation of the Pilot Lab}

The design of the Pilot Lab aimed at the construction of an experimental device, which allows to inject "contaminated solution" under controlled condition in a water circuit and to track the response of water quality devices to this injection. Figs 1 and 2 show the Pilot. It is composed of $16 \mathrm{~mm}$ opaque double layer pipes, water tanks for filling and emptying, a system for injecting chemical or biological products, pumps, valves, manometers and flow sensors. The total length of water pipes is equal to $61 \mathrm{~m}$.

An injection system is used to introduce chemical or biological products in the water circuit. Sensors are used to track the pressure at different points of the water circuit. Water quality devices are connected at $41 \mathrm{~m}$ from the "contaminated solution" injection section. 


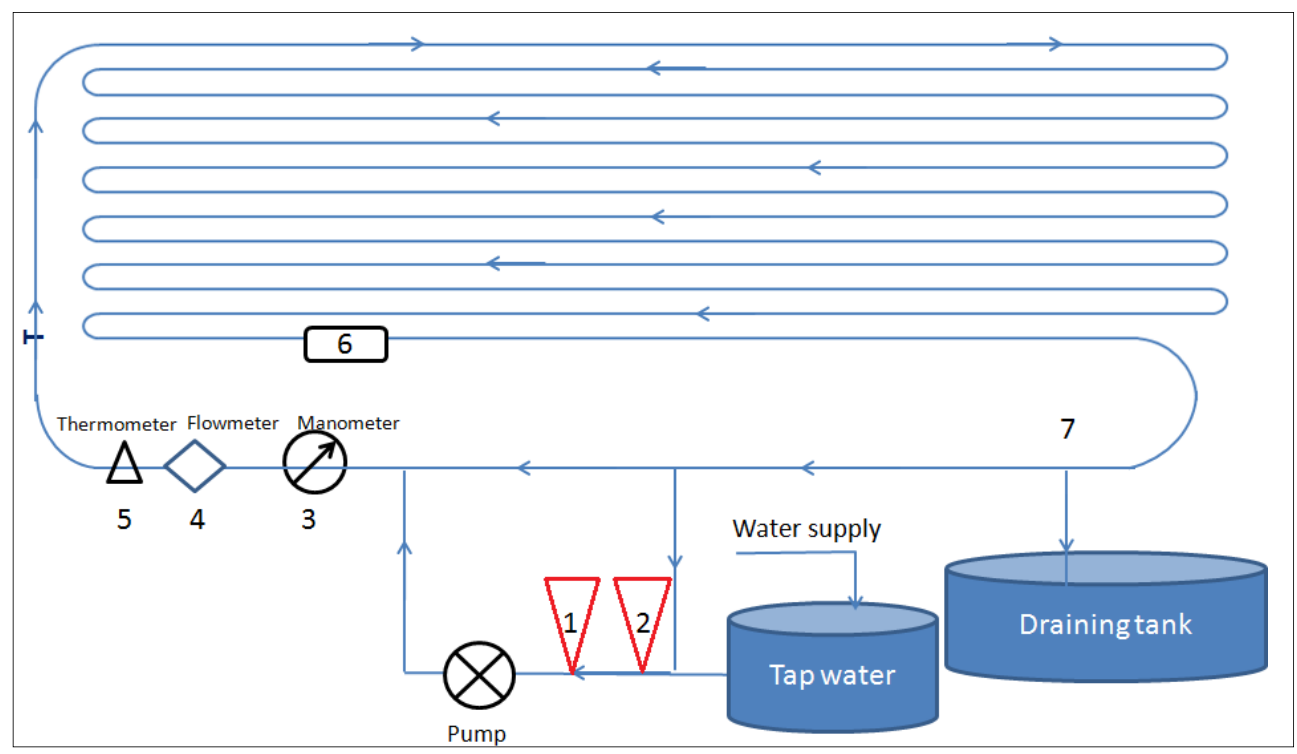

Figure 1: Laboratory-scale network.

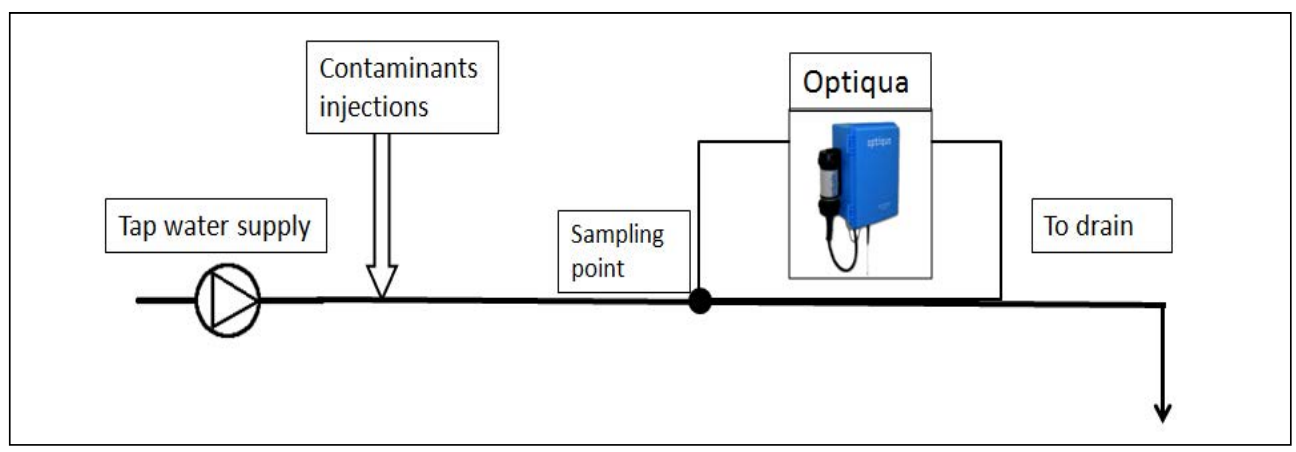

Figure 2: Experimental set-up at the sensor lab.

\subsection{EventLab (Optiqua) device}

EventLab (Optiqua) is an optical-based device that measures the change in the water refractive index, using the Mach Zehnder Interferometry (MZI) principle [9], [10]. This Index is a good indicator of the water quality; because the presence of a substance in the water leads to a change in this index. EventLab operates at a sensitivity level of 10-7 in the refractive index. In addition to the MZI chip, EventLab includes electronics, software, data algorithms, and data communication [10].

The output signal of the sensor is the phase shift in the light passing through the sensor due to the presence of a substance. The phase shift variation is related to the variation in the refractive index. Since the water temperature affects the water refraction index [11], recorded data are adjusted in order to take into consideration the effect of temperature. 


\subsection{Experimental procedure}

Experiments were conducted as follows. First, the water circuit was cleaned for 30 minutes, then a baseline output was established by the injection of tap water for 60 minutes. After stabilization of the baseline, the "contaminated solution" was injected in the water circuit. By the end of the test, the water circuit was cleaned, disinfected and dried with compressed air to prevent the formation of bio films.

\section{RESULTS}

Fig. 3 shows the results of an experiment conducted by successive injection of mercury chloride $\left(\mathrm{HgCl}_{2}\right)$. It illustrates the variation in the compensated phase during the test. The time interval between two successive injections is 20 minutes, while the injection time is

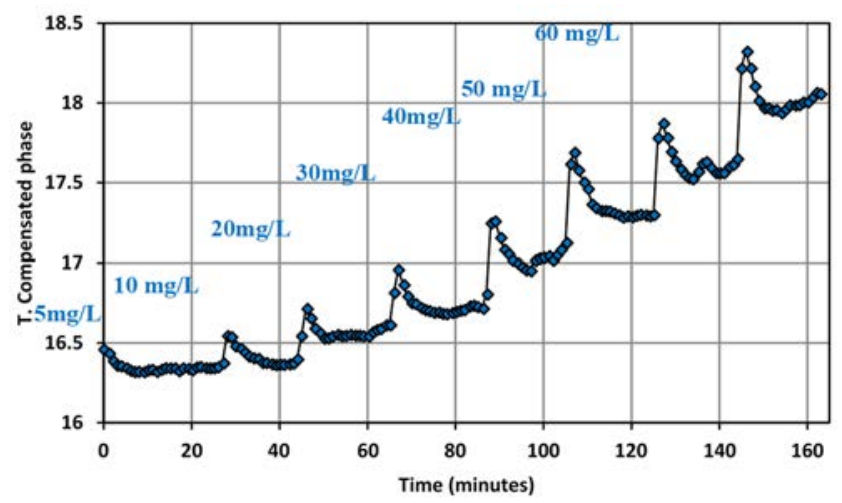

Figure 3: Optiqua EventLab response as a function of the cumulative concentration level of $\mathrm{HgCl}_{2}$.

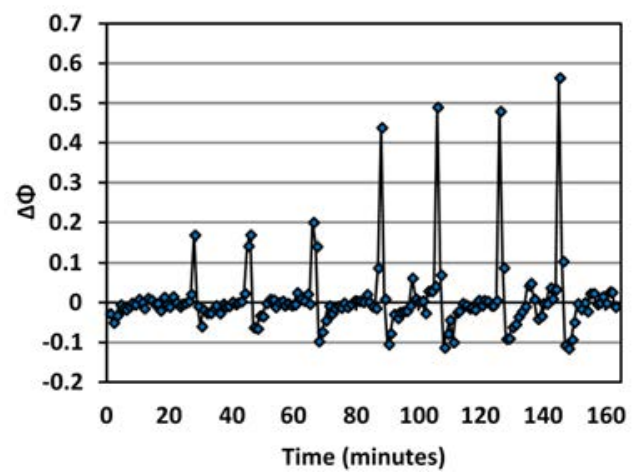

(a) Delta phase variation during injection test.

\begin{tabular}{|c|c|}
\hline $\begin{array}{c}\text { Added } \\
\text { concentration } \\
{[\mathrm{mg} / \mathrm{L}]}\end{array}$ & Maximum $\Delta \Phi$ \\
\hline 0 & 0 \\
\hline 5 & 0.17075 \\
\hline 10 & 0.17097 \\
\hline 20 & 0.20245 \\
\hline 30 & 0.44088 \\
\hline 40 & 0.49246 \\
\hline 50 & 0.48220 \\
\hline 60 & 0.56646 \\
\hline
\end{tabular}

(b) Variation of the maximum delta phase with the solution concentration.

Figure 4: EventLab response to the injection of a solution with $\mathrm{HgCl}_{2}$. 
equal to 3 minutes. The figure shows clearly the response of EventLab to the injection events and the increase in the amplitude of the response with the increase in the solution concentration.

Experiments were also conducted with cadmium chloride, sodium hypochlorite and glyphosate. Results of these tests are summarized in Figs 5-7. These results show that EventLab detects the introduction of any of these substances at a concentration exceeding $5 \mathrm{mg} / \mathrm{L}$. The relationship between the solution concentration and the phase increment is quasi- linear with a regression coefficient higher than 0.8 .

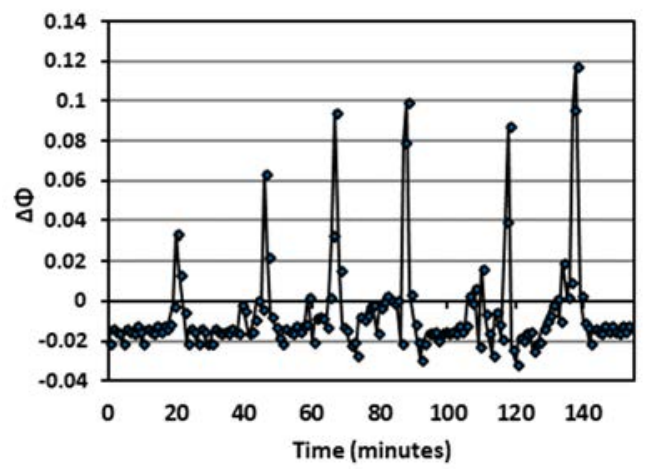

(a) Delta phase variation during injection test.

\begin{tabular}{|c|c|}
\hline $\begin{array}{c}\text { Added } \\
\text { Concentration } \\
{[\mathrm{mg} / \mathrm{L}]}\end{array}$ & $\begin{array}{c}\text { Maximum } \\
\Delta \Phi\end{array}$ \\
\hline 0 & 0 \\
\hline 10 & 0.03467 \\
\hline 20 & 0.06450 \\
\hline 40 & 0.09491 \\
\hline 50 & 0.10000 \\
\hline 60 & 0.08802 \\
\hline 70 & 0.11785 \\
\hline
\end{tabular}

(b) Variation of the maximum delta phase with the solution concentration.

Figure 5: EventLab response to the injection of a solution with $\mathrm{CdCl}_{2}$.

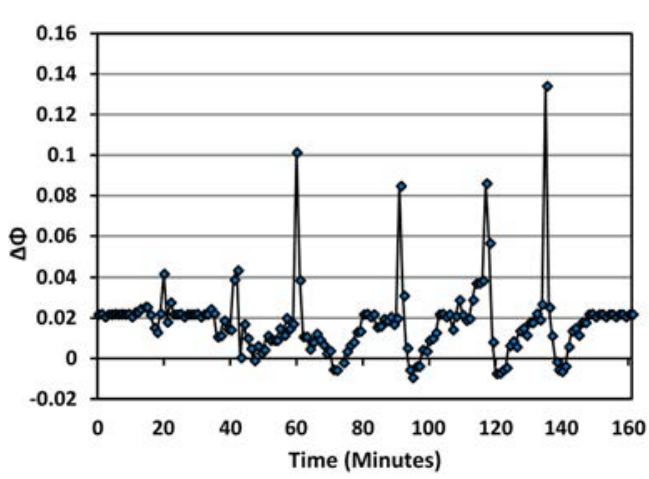

(a) Delta phase variation during injection test.

\begin{tabular}{|c|c|}
\hline $\begin{array}{c}\text { Added } \\
\text { Concentration } \\
{[\mathrm{mg} / \mathrm{L}]}\end{array}$ & $\begin{array}{c}\text { Maximum } \\
\Delta \Phi\end{array}$ \\
\hline 0 & 0 \\
\hline 5 & 0 \\
\hline 10 & 0.042273 \\
\hline 20 & 0.04300 \\
\hline 30 & 0.101707 \\
\hline 40 & 0.085288 \\
\hline 50 & 0.086481 \\
\hline 60 & 0.134593 \\
\hline
\end{tabular}

(b) Variation of the maximum delta phase with the solution concentration.

Figure 6: EventLab response to the injection of a solution with $\mathrm{NaClO}$. 


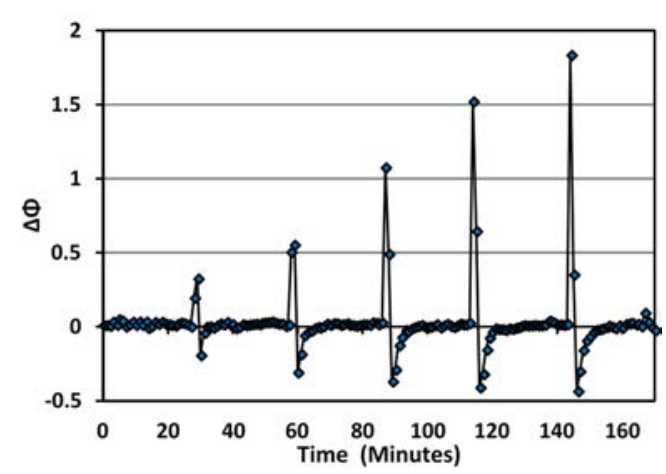

(a) Delta phase variation during injection test.

\begin{tabular}{|c|c|}
\hline $\begin{array}{c}\text { Added } \\
\text { concentration }\end{array}$ & Maximum $\Delta \Phi$ \\
\hline 0 & 0 \\
\hline 5 & 0.531639 \\
\hline 10 & 1.069637 \\
\hline 20 & 1.578406 \\
\hline 30 & 2.178423 \\
\hline 40 & 2.198035 \\
\hline
\end{tabular}

(b) Variation of the maximum delta phase with the solution concentration.

Figure 7: EventLab response to the injection of a solution with $\mathrm{C}_{3} \mathrm{H}_{8} \mathrm{NO}_{5} \mathrm{P}$.

\section{CONCLUSION}

This paper included the presentation of an experimental investigation of the capacity of an optical-based device (EventLab) to detect in real-time water chemical contamination. Tests were conducted in a Pilot Lab within the European project SmartWater4Europe. They included the injection of different chemical substances (Cadmium chloride, Mercury chloride, Sodium hypochlorite and Glyphosate) at different concentrations. Tests showed that EventLab detected the injection of these substances at a concentration exceeding $5 \mathrm{mg} / \mathrm{L}$. The relationship between the substance concentration and maximum delta phase is quasilinear with a regression coefficient higher than 0.8. This study shows that EventLab is efficient for a real-time detection of water chemical contamination.

\section{REFERENCES}

[1] Helbling, D.E. \& VanBriesen, J.M., Continuous monitoring of residual chlorine concentrations in response to controlled microbial intrusions in a laboratory-scale distribution system. Water Research, 42(12), pp. 3162-3172, 2008.

[2] Payment, P. \& Hartemann, P., Les contaminants de l'eau et leurs effets sur la santé. Revue des sciences de l'eau. Journal of Water Science, 11, pp. 199-210, 1998.

[3] Guepie, F.C.B.K. et al., Vigires' eau: système de surveillance en temps réel de la qualité de l'eau potable d'un réseau de distribution en vue de la détection d'intrusion, 2013.

[4] Jain, S. \& McLean, C.R., An integrating framework for modeling and simulation for incident management. Journal of Homeland Security and Emergency Management, 3(1), 2006.

[5] Panguluri, S. et al., Distribution system water quality monitoring: Sensor technology evaluation methodology and results. US Environ. Protection Agency, Washington, DC, USA, Tech. Rep. EPA/600/R-09/076, 2772, 2009.

[6] Yang, Y.J. et al., Adaptive monitoring to enhance water sensor capabilities for chemical and biological contaminant detection in drinking water systems, 2006.

[7] van Wijlen, M. et al., Innovative sensor technology for effective online water quality monitoring. Proceedings of the 4th Singapore International Water Week, 2011. 
[8] Kemmerer, R.A. \& Vigna, G., Intrusion detection: a brief history and overview. Computer, 35(4), pp. 27-30, 2002.

[9] Heideman, R.G. \& Lambeck, P.V., Remote opto-chemical sensing with extreme sensitivity: design, fabrication and performance of a pigtailed integrated optical phasemodulated Mach-Zehnder interferometer system. Sensors and Actuators B, Chemical, 61(1), (3), pp. 100-127, 1999.

[10] Tangena, B. et al., A novel approach for early warning of drinking water contamination events. Proceedings of the 4th International Conference on Water Contamination Emergencies: Monitoring, Understanding, Acting, 11-13 Oct. 2010, Mullheim, 2011.

[11] Thormählen, I., Straub, J. \& Grigull, U., Refractive index of water and its dependence on wavelength, temperature, and density. Journal of Physical and Chemical Reference Data, 14(4), pp. 933-945, 1985. 